\title{
A Microscopic and Metabolomic Description of Stip-affected Tissue in New Mexico Pod-type Pepper
}

\author{
James C. Fulton \\ Department of Plant Pathology, University of Florida, 2550 Hull Road, Gainesville, \\ FL 32611-0680 \\ Francisco O. Holguin \\ Department of Plant and Environmental Sciences, New Mexico State University, \\ Box 30003 MSC 3Q, Las Cruces, NM 88003-8001 \\ Robert L. Steiner \\ Economics, Applied Statistics, \& International Business Department, New Mexico State \\ University, 1320 East University Avenue, Las Cruces, NM 88003-8001 \\ Mark E. Uchanski \\ Horticulture and Landscape Architecture, Colorado State University, 1173 Campus Delivery, \\ Fort Collins, CO 80523-1173
}

\begin{abstract}
AdDitional InDEX words. abiotic disorder, Capsicum annuum, field-grown, microscopy, physiological disorder
Abstract. Stip is a physiological disorder that affects certain pepper (Capsicum annuum) cultivars, most notably bell-pod types. It has been attributed in the literature to nutrient imbalances, temperature extremes, and/or other environmental stressors. Symptoms present as brown, black, and yellow ovoid-shaped necrotic lesions $\approx 0.5$ to $1.2 \mathrm{~cm}$ long by $0.5 \mathrm{~cm}$ wide. Between 2014 and 2015, symptomatic and asymptomatic pods were harvested from 15 commercial farms in southern New Mexico. Fluorescent microscopy comparisons of harvested symptomatic tissue revealed a unique fluorescent signature and the absence of chlorophyll. A new spectral peak centered around $560 \mathrm{~nm}$ was observed in symptomatic tissue. High-performance liquid chromatography (HPLC) and gas chromatography-mass spectrometry (GC-MS) analyses of these tissues detected significant differences in 13 metabolites, of which several have been associated with fruit maturation and/or senescence. This report represents the first combination of a detailed microscopic description and metabolite profile of field-grown symptomatic plants with this disorder.
\end{abstract}

Stip is regarded as a physiological disorder of pepper (Capsicum annuum) in which symptoms appear as brown, black, and yellow ovoid-shaped chlorotic and/or necrotic pod lesions $\approx 0.5$ to $1.2 \mathrm{~cm}$ long and $0.5 \mathrm{~cm}$ wide (Fulton and Uchanski, 2017; Fulton et al., 2021) (Fig. 1). A single lesion may be present on symptomatic pods, but often 15 or more will occur. Lesions occasionally have a clear boundary; however, lesions can coalesce if they present in large numbers. In addition, lesions are often found in the middle third of fully developed pepper pods and can be present on mature green and red fruit. Although plants appear otherwise unaffected, the lesions make the fruit unmarketable. Because previous research has failed to identify any culpable pathogen, stip is believed to be a physiological disorder

Received for publication 6 Oct. 2020. Accepted for publication 5 Feb. 2021

Published online 20 April 2021.

Funding for this research was provided by the New Mexico Chile Association. Additional salaries and research support were provided by state and federal funds appropriated to the New Mexico Agricultural Experiment Station.

We thank Mike Petersen and Dustin Ward for their technical assistance. We emphasize the invaluable support provided by Peter H. Cooke and New Mexico State University's Microscopic Imaging Core Suite (MICS) during microscopic analysis and manuscript preparation. We also thank Diane M. Blietz for her diligent proofreading of this work.

M.E.U. is the corresponding author. E-mail: mark.uchanski@colostate.edu. This is an open access article distributed under the CC BY-NC-ND license (https://creativecommons.org/licenses/by-nc-nd/4.0/). caused by environmental stressors (Hibberd, 1981; Villalon, 1975). Excess nitrogen fertilization, inadequate light, elevated soil $\mathrm{pH}$, and lime applications have been identified as possible contributing factors (Aloni et al., 1994; Feigin and Sagiv, 1987; Hibberd, 1981; Smith et al., 1995). Aloni et al. (1994) investigated the relationship between excess nitrogen fertilization and symptom expression, and evaluated the effect light and the amount of nitrogen fertilization had on three bell-podtype cultivars (Maor, Lady Bell, and 899), which varied in their degree of susceptibility to stip. They reported an increase in the quantity of intracellular oxalic acid in tandem with increased applications of nitrogen, particularly in lightlimited environments. Furthermore, when viewed under a scanning electron microscope, Aloni et al. (1994) observed crystalline structures hypothesized to be calcium oxalate or chelated oxalic acid. They concluded that stip lesions could be the result of chelated oxalic acid puncturing cell membranes, leading to subsequent cell death and oxidation.

Metabolomics research examining the relative importance of oxalic acid and other small molecular metabolites would advance this prior research. Previous metabolomics research has examined the significance of intracellular calcium in response to cold, phytohormone regulation influenced by heat stress, and the effect of drought on biochemistry (Escandón et al., 2018; Michailidis et al., 2017; Moradi et al., 2017). Similarly, a detailed 


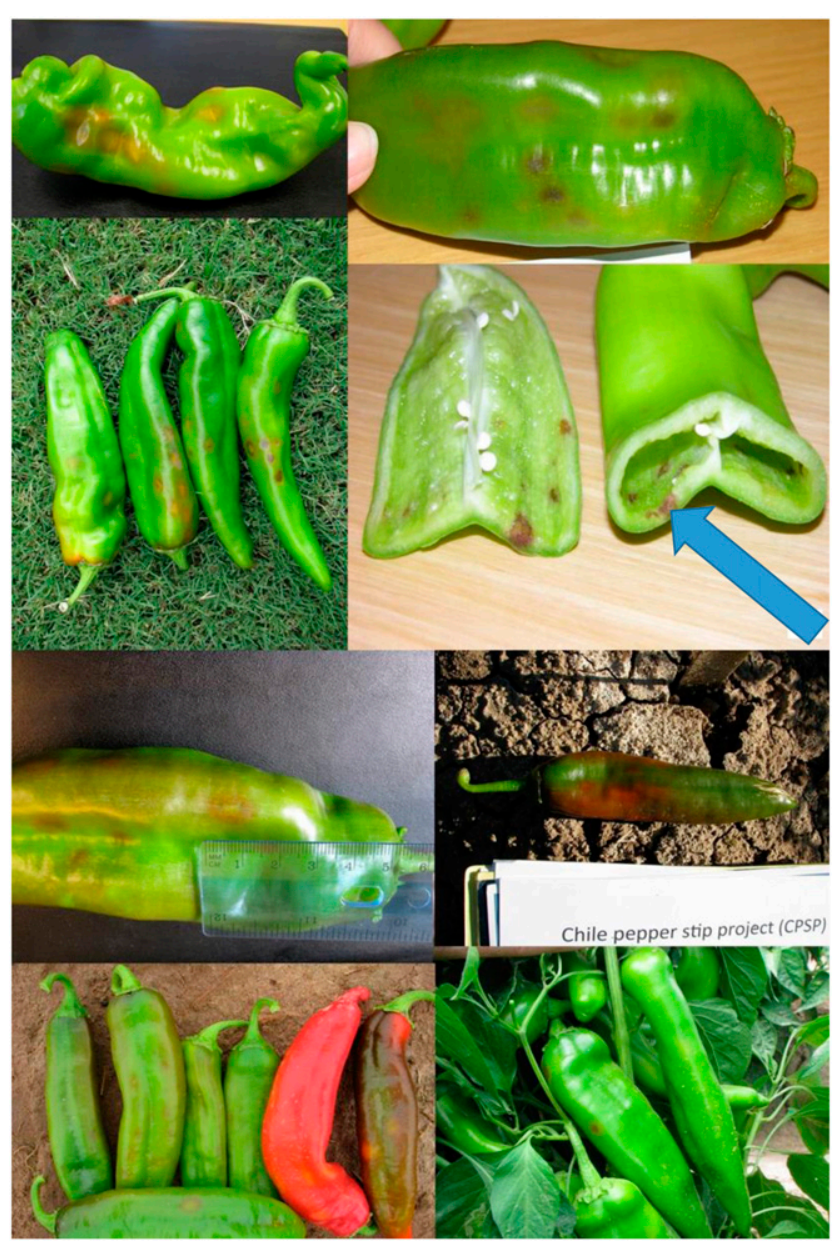

Fig. 1. A collage of stip symptoms on New Mexico pod-type, field-grown peppers showing the range of colors, shapes, sizes, and levels of severity. The blue arrow indicates tissue necrosis inside the pod wall.

metabolomics and microscopic description of stip-affected tissue would establish the description of this disorder, identify potential metabolites involved during symptom expression, and provide insight into the underlying physiological mechanism leading to symptom development.

\section{Materials and Methods}

\section{Field visit procedure}

YEAR 1 (2014). Six commercial fields in southern New Mexico, with significant amounts of stip reported by industry field managers, were visited between 4 Aug. and 25 Sept. 2014. Mature green pods from cultivar AZ 1904 were sampled from locations within the fields that generally followed the same cultivation practices (including irrigation, fertilizer application, and pesticide treatment) and environmental conditions. Upon collection, pods were identified and grouped into one of four unique categories: i, asymptomatic pods from asymptomatic plants; ii, asymptomatic pods from symptomatic plants; iii, asymptomatic tissue from symptomatic pods; and iv, symptomatic stip lesion tissue from symptomatic pods (Fig. 2). An intake form was recorded for each collected pod with a photo, date, sampling location, cultivar, pod category, and cultivation practices.

Within $48 \mathrm{~h}$ of collection, tissue (diameter, $\approx 1.5 \mathrm{~cm}$ ) was excised from harvested pod material. About half the excised material was flash-frozen in liquid nitrogen, whereas the residual amount was examined microscopically. Frozen samples were dried in a lyophilizer (SP Scientific, Warminster, PA) for $4 \mathrm{~d}$ at less than 13.3 $\mathrm{Pa}$ pressure at about $-40^{\circ} \mathrm{C}$. Dry tissue was then homogenized using a mortar and pestle, weighed to $6 \mathrm{mg}$, and stored at $-20^{\circ} \mathrm{C}$ until metabolomics testing.

YEAR 2 (2015). The same procedure described for year 1 was followed in 2015, with the following modifications: pods from all categories were collected from five commercial fields, followed by visits to four additional fields later in the season to collect more symptomatic pod tissue. This provided a greater number of pods and tissue to analyze in year 2 .

\section{Microscopy procedures}

Stereo fluORESCENCE MiCROSCOPy. Before use, excised plant tissue was stored at $4{ }^{\circ} \mathrm{C}$ with limited ambient light exposure. However, within $72 \mathrm{~h}$ of collection, pepper tissue underwent stereo fluorescence and confocal microscopic imaging (Leica Microsystems, Wetlzar, Germany). Before examination of the fruit pericarp, the tissue samples were trimmed to $\approx 1 \mathrm{~cm}$ long, 0.3 to $0.5 \mathrm{~cm}$ wide, and 0.3 to $0.5 \mathrm{~cm}$ deep. A fluorescent phenotype from all tissue categories was observed. In symptomatic tissue (stip lesion) samples, a region of asymptomatic tissue was left around the periphery of symptomatic tissue. Tissue samples were then viewed in cross-section, which showed vascular bundles. The tissue was then placed in a 35-mm glass-bottom microwell dish (MatTek Corp., Ashland, MA) and set on top of a solid-black surface to limit light reflection.

After samples were positioned, ambient lighting was reduced, the focus and magnification set, and an initial image using the reflection lamp setting was taken to include the date, name, and other pertinent information for each sample. Fluorescence images were then collected using the green fluorescent protein (GFP), Texas Red (TXR), violet, and ultraviolet filter sets. The settings on the software were as follows: zoom $2.0 \times, 3.3$ gain, 1.00 saturation, and 1.00 gamma. The exposure times were 2.99 ms (lamp), $3.0 \mathrm{~s}$ (GFP), $2.0 \mathrm{~s}$ (TXR), $2.0 \mathrm{~s}$ (violet), and $5.0 \mathrm{~ms}$ (ultraviolet). Proprietary application suite advanced fluorescence software (version 2.7.2.9586, Leica Microsystems) was used to acquire the images.

Confocal Microscopy. Confocal microscopy was incorporated to gain precision and depth, and to limit possible fluorescence from peripheral areas to areas at the exact focal plane of the lens. This approach allowed for greater definition in the fluorescent signal. In addition, this provided a comparison between the fluorescent signal observed with the stereo fluorescent microscope and the fluorescence seen using the higher resolution confocal microscope.

After capturing stereo fluorescence images of dissected pericarp from selected fruit, a laser scanning confocal microscope (TCS SP5, Leica Microsystems) with a long working distance $(1.15 \mathrm{~mm}) 20 \times$ objective lens was used to capture confocal imagery. Identical software as described previously was used to acquire the images. A scan of the sample area with a 488-nm argon ion laser at $20 \%$ power resulted in fluorescence excitation. Frameaveraged fluorescence emission was collected in two separate data channels: one at 500 to $550 \mathrm{~nm}$ (green) and the other at 650 to 


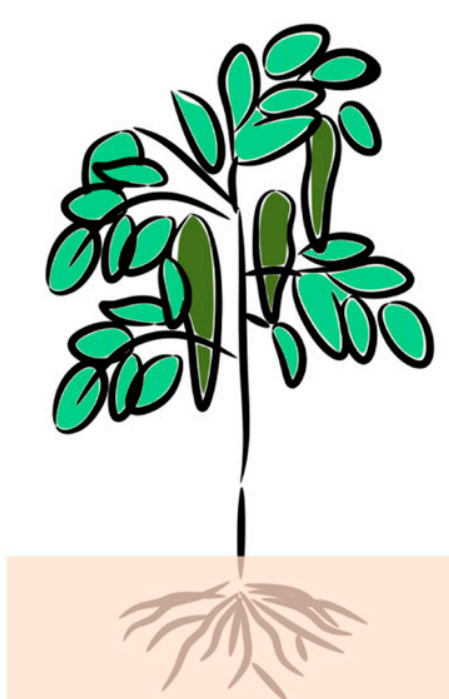

Asymptomatic pod from asymptomatic plant (i)

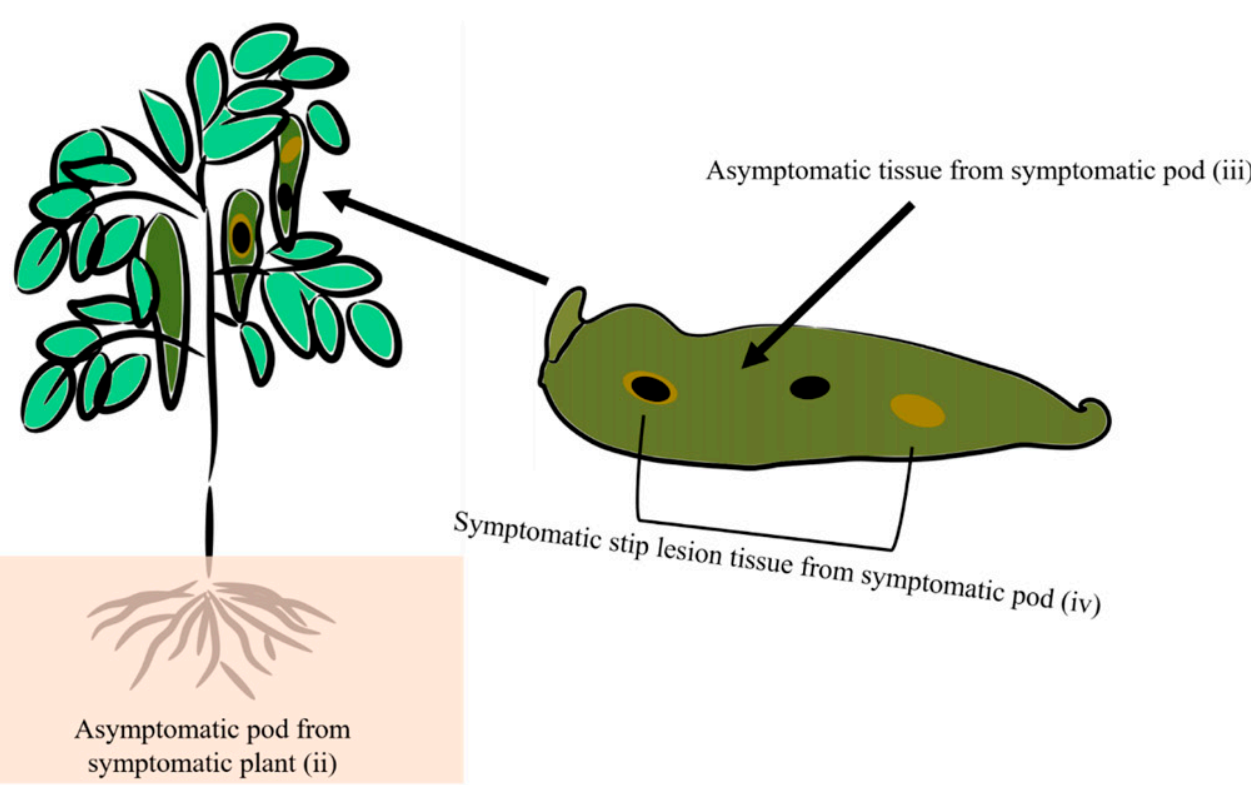

symptomatic plant (ii)

Fig. 2. An illustration of the pepper pod collection procedure used while sampling at commercial fields in southern New Mexico between 2014 and 2015 . During sampling, individual harvested pods were categorized into one of four different classes: i, asymptomatic pod from asymptomatic plant; ii, asymptomatic pod from symptomatic plant; iii, asymptomatic tissue from symptomatic pod; and iv, symptomatic stip lesion tissue from symptomatic pod.

$700 \mathrm{~nm}$. Maximum projection images of 30 - to $40-\mu \mathrm{m}$-thick tissue slabs composed of 40 to 50 optical sections were captured. Fluorescence emission spectra from 500 to $750 \mathrm{~nm}$ were captured using the lambda scan tool with a bandwidth of $\approx 20 \mathrm{~nm}$.

\section{Metabolomics procedures}

High-PERFormanCe liquid Chromatography. An abridged version of the protocol described by Richins et al. (2014) was followed for HPLC. During the first year, $6 \mathrm{mg}$ of tissue per sample was extracted; the following year, $25 \mathrm{mg}$ per sample was used. Samples were saponified with $1 \mathrm{~mL}$ of $2 \mathrm{~N}$ methanolic potassium hydroxide, vortexed for $30 \mathrm{~s}$, and heated at $50^{\circ} \mathrm{C}$ for 1 $\mathrm{h}$. They were then stored in a dark environment for $24 \mathrm{~h}$. Afterward, they were centrifuged at $4{ }^{\circ} \mathrm{C}$ for $20 \mathrm{~min}$ at $2900 \mathrm{~g}_{\mathrm{n}}$, and the supernatant was passed through a syringe filter (Sigma-Aldrich, St. Louis, MO). Fifty-microliter sample injections were run at $25^{\circ} \mathrm{C}$ on an HPLC with an attached photodiode array detector (400- to 600-nm detection; Waters Alliance, Milford, MA) equipped with a carotenoid-specific column (YMC, Allentown, PA). After every 10 tissue samples, a reference sample consisting of $\beta$-carotene was run to confirm equipment precision. The binary solvent system used was $81 \%$ methanol, $15 \%$ methyl tert-butyl ether, $4 \%$ deionized water and $90 \%$ methyl tert-butyl ether, $6 \%$ methanol, and $4 \%$ deionized water with a flow rate of $1 \mathrm{~mL} \cdot \mathrm{min}^{-1}$.

GaS CHROMATOGRAPHY-MASS SPECTROMETRY. GC-MS was used to compare polar metabolite concentrations statistically across the four tissue classes. Sample preparation was completed as described by Boeckling et al. (2006) with slight modifications: the use of a centrifugal evaporator to dry the nonpolar layers (Eppendorf, Hauppauge, NY) and the addition of $60 \mu \mathrm{L}$ of internal retention index markers for quality control (SigmaAldrich). The instrumentation was washed two times with $1 \mu \mathrm{L}$ of an equal mixture of ethyl acetate, acetonitrile, and isobutyl followed by two washes with hexane. Samples were run on a
GC-MS time-of-flight machine (Agilent Technologies, Santa Clara, CA) using proprietary software (ChromaTOF version 4.41; LECO, St. Joseph, MI).

Individual peaks were identified using a published library (Kind et al., 2009) and were verified by plotting the retention index numbers against their elution time (Kind et al., 2009). Data from generated files were extracted and aligned with Met IDEA v. 2.08 (Samuel Roberts Noble Foundation, Ardmore, OK). The resulting peak concentrations were then normalized by dividing them by the ribitol peak concentration and then by the sample's mass. To ascertain concentrations of metabolites, peak areas were correlated to the known ribitol concentration and its peak area. The resulting data were then analyzed as described next.

\section{Statistical analysis}

Analysis of variance was calculated for the polar metabolite and carotenoid concentrations using the Proc GLM Model (SAS version 9.4; SAS Institute, Cary, NC), and global f-test and pairwise comparisons were applied at $10 \%(\alpha=0.10)$. The categories - asymptomatic pod from asymptomatic plant tissue [i (this category was replicated 11 times)], asymptomatic pod from symptomatic plant (ii), asymptomatic tissue from symptomatic pod (iii), and symptomatic stip lesion tissue from symptomatic pod tissue (iv) - were replicated 15 times. Post hoc tests of metabolite concentration differences between the tissue classes' least squares means were assessed using Tukey's honestly significant difference (HSD) test. Chromatographic data were normalized on an individual metabolite basis with either the log base 10, square root, or natural log transformation, depending on which fit the data best; the year was included in the analysis as a fixed factor. Interaction between tissue class and harvest date was first examined; the null hypothesis regarding the interaction between years and tissue was not rejected for any of the 
metabolites studied except citric acid. Therefore, samples across years were combined to increase the power of statistical tests.

\section{Results}

\section{Microscopy results}

Stereo FluORESCEnCE. Figure 3A and B shows excised pod tissue collected from asymptomatic plants, and Fig. 3C and D shows symptomatic stip lesion tissue. In addition, Fig. 3A and $\mathrm{C}$ was acquired using a violet filter, whereas Fig. 3B and D used a GFP filter. This comparison presents the distinct fluorescent phenotype unique to stip lesion tissue. Only symptomatic areas, and not the surrounding asymptomatic tissue, displayed this distinct fluorescence. Often, the location of fluorescence symptoms was about equidistant between two vascular bundles, as indicated with the small blue arrow in Fig. 3C. Furthermore, neither tissue from an asymptomatic pod from a symptomatic plant (tissue category ii) nor asymptomatic tissue from a symptomatic pod (tissue category iii) showed this fluorescent phenotype (Fig. 4). Microscopically, there were no noticeable distinctions between the various stages of asymptomatic tissue (tissue categories i, ii, and iii) (Fig. 4).

The pattern of fluorescence seemed to progress during symptom development. During the earlier stages of symptom expression, when lesions were difficult to detect, the autofluorescence of chlorophyll was extinguished. Simultaneously, a background fluorescence appeared, possibly of a carotenoid pigment, as shown by the large yellow arrow in Fig. 3C. However, as the disorder progressed and lesions became more defined, this area lost fluorescence. As shown by the red arrow in Fig. 3D, when lesions were fully formed, all fluorescence was absent.

Confocal FluORESCEnCE. Confocal microscopy confirmed the unique fluorescent phenotype observed in symptomatic stip lesion tissue from a symptomatic pod (tissue category iv) (Fig. 5). As observed previously, only in symptomatic areas with necrotic or chlorotic lesions was this fluorescence detected. Confocal microscopy also revealed that the majority of this fluorescence was coincident with individual cell walls and was not observed within the cell interior. In addition, there appeared to be significantly fewer chloroplasts in stip-affected tissue compared with asymptomatic tissue. These distinctions were noted only in symptomatic tissue, whereas tissue from the tissue categories i, ii, and iii appeared uniform (Fig. 5).

Emission spectral data were collected from the 500- to 740-nm wavelength range and is shown in Fig. 6. Asymptomatic tissue showed a prominent peak centered on $680 \mathrm{~nm}$, which corresponds with the emission wavelength of chlorophyll $\alpha$ (narrow line in Fig. 6). In comparison, the abundance of chlorophyll $\alpha$ showed a significant decrease in symptomatic tissue congruent with the visual observation of chlorophyll loss in stip lesions discussed previously (thick line in Fig. 6). However, emission spectra centered around $680 \mathrm{~nm}$ were observed possibly as a result of peripheral asymptomatic tissue surrounding stip lesions or the residual presence of a few chloroplasts in symptomatic tissue.

\section{Metabolomic results}

High-PERFORMANCE LIQUID CHROMATOGRAPHY. Quantified metabolite concentrations in the four tissue categories were found to follow one of four distinct metabolite profiles or trends

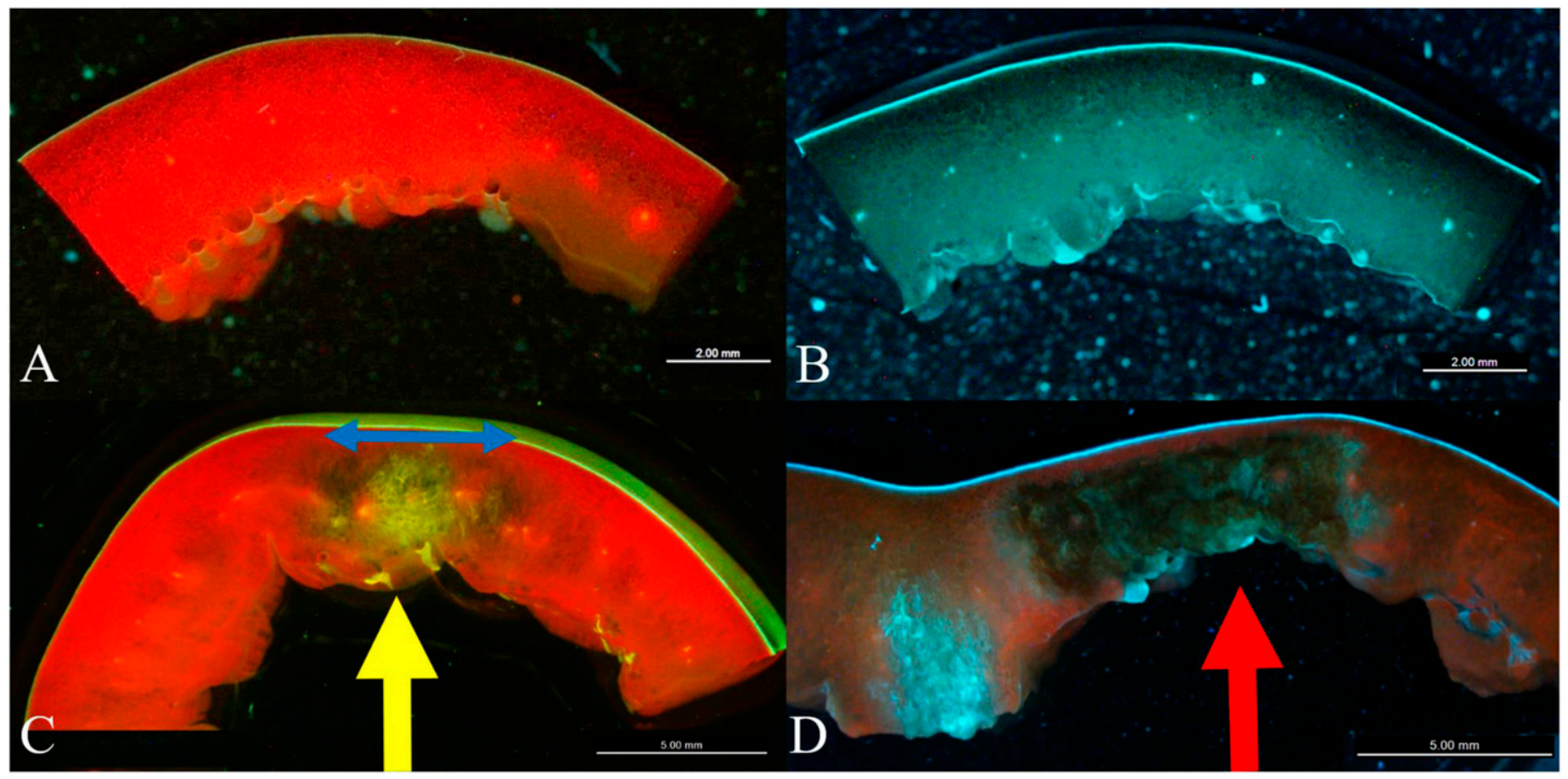

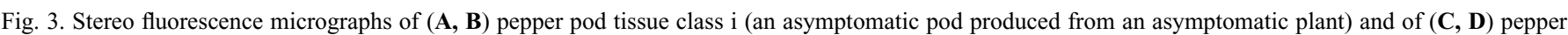
pod tissue class iv (symptomatic stip lesion tissue excised from a symptomatic pod). The blue arrow in (C) indicates the location of stip symptoms between vascular bundles, the yellow arrow designates a developing stip lesion and new fluorescence, and the red arrow indicates a mature stip lesion and absence of fluorescence. $(\mathbf{A}, \mathbf{C})$ Generated with a violet light cube. $(\mathbf{B}, \mathbf{D})$ Generated with a green fluorescent protein filter cube. $(\mathbf{A}, \mathbf{B})$ Bar $=2$ mm. $(\mathbf{C}, \mathbf{D})$ $\mathrm{Bar}=5 \mathrm{~mm}$. 
Asymptomatic pod from asymptomatic plant (i)

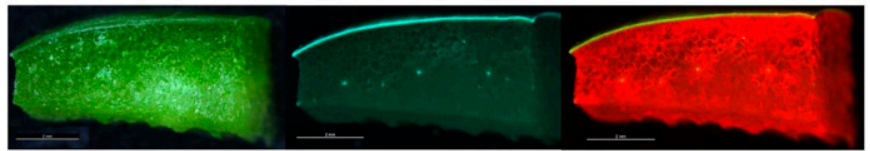

Asymptomatic pod from symptomatic plant (ii)

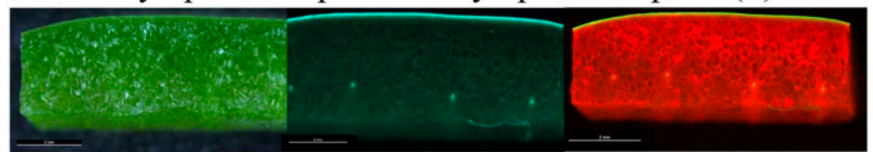

Asymptomatic tissue from symptomatic pod (iii)

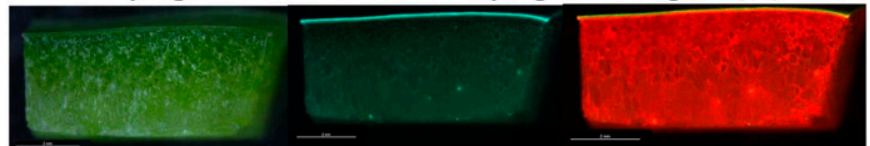

Symptomatic stip lesion tissue from symptomatic pod (iv)

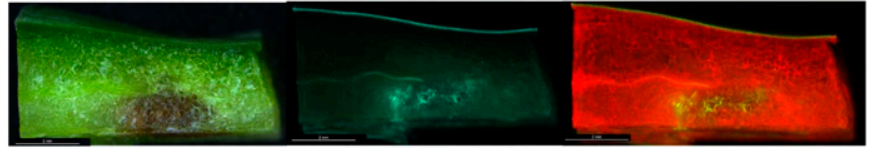

Fig. 4. Stereo fluorescence imagery of the four described tissue classes (i, ii, iii, and iv) from New Mexican pod-type pepper. Green fluorescent protein and violet light filters were used in the middle and rightmost images, respectively. Of the four tissue types studied, two visually distinct groups were apparent: asymptomatic and symptomatic. Bar $=2 \mathrm{~mm}$.

(Fig. 7). These profiles describe the general trends of tested metabolites as tissue progressed from asymptomatic to symptomatic lesions. For example, in trend 1, a metabolite's concentration in the symptomatic tissue category (iv) was elevated in relation to tissue categories i, ii, and iii, and no tissue class was observed with an intermediate concentration. The inverse of this pattern was observed in trend 2, in which a metabolite's concentration in the symptomatic tissue category (iv) was depressed in relation to tissue categories i, ii, and iii, and no tissue class was observed with an intermediate concentration. Metabolites grouped into trends 3 and 4 were observed at an intermediate concentration between that found in tissue categories $i$ and ii relative to symptomatic tissue. For example, in trend 3, a metabolite's concentration in the symptomatic tissue category (iv) was elevated in relation to tissue categories $\mathrm{i}$ and ii, whereas iii fell somewhere intermediate between iv, and i and ii tissue categories. Last, similar to trend 3, metabolites that followed general trend 4 were observed at an intermediate concentration in tissue category iii, whereas the concentration was significantly less in symptomatic tissue (iv) relative to tissue categories i and ii. The outcome for each carotenoid and metabolite is summarized in Table 1.

HPLC allowed for the comparison of the carotenoid pigments lutein, capsanthin, and zeaxanthin among the four tissue categories. Lutein concentration was observed to follow general trend 2. Its concentration in symptomatic tissue (iv) was significantly less than that present in tissue categories i, ii, and iii $(P<0.0001)$. Capsanthin and zeaxanthin concentrations displayed trend 3. Capsanthin was not detected in tissue categories $\mathrm{i}$ and ii, but its concentration increased gradually within tissue category iii and reached its highest amount within symptomatic tissue (iv). Because of the complete absence of capsanthin in tissue categories i and ii, post hoc statistical analysis was not conducted. Zeaxanthin was observed at a significantly greater concentration in symptomatic tissue relative to tissue categories i $(P<0.0001)$ and ii $(P<0.0001)$, whereas the concentration in tissue category iii was also significantly greater than tissue categories i $(P<0.05)$ and ii $(P<0.01)$.

GAS CHROMATOGRAPHY-MASS SPECTROSCOPY. Concentration comparisons for four representative metabolites (malic acid, galactose 1, citric and oxalic acid), each described by the aforementioned general trends, is shown in Fig. 8. The results of individual post hoc (Tukey's HSD) comparisons among the tissue

Asymptomatic pod from asymptomatic plant (i)

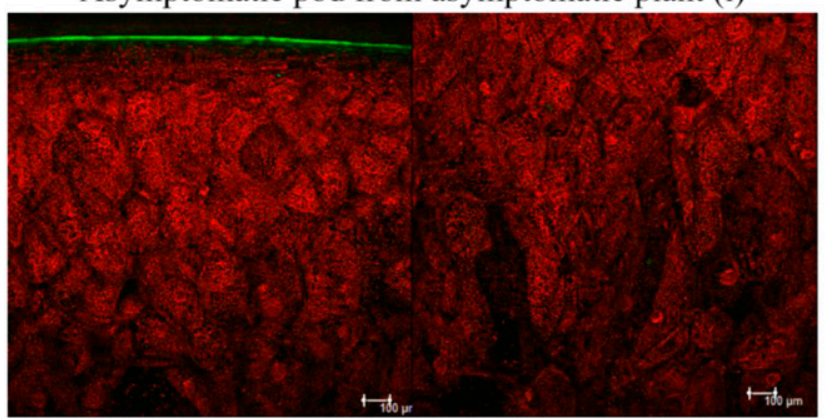

Asymptomatic pod from symptomatic plant (ii)

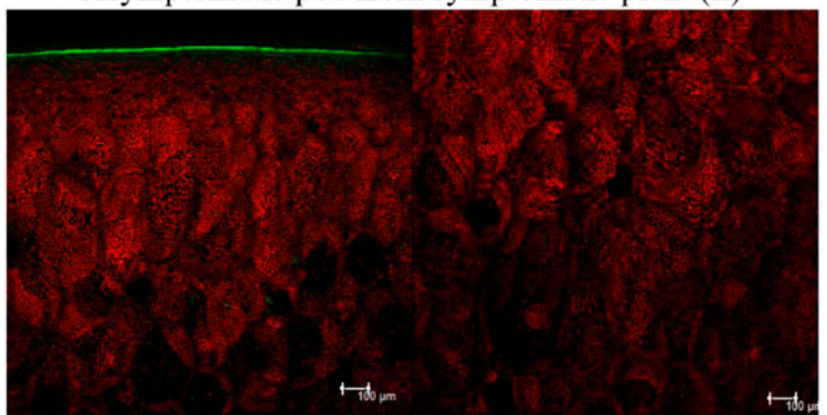

Asymptomatic tissue from symptomatic pod (iii)

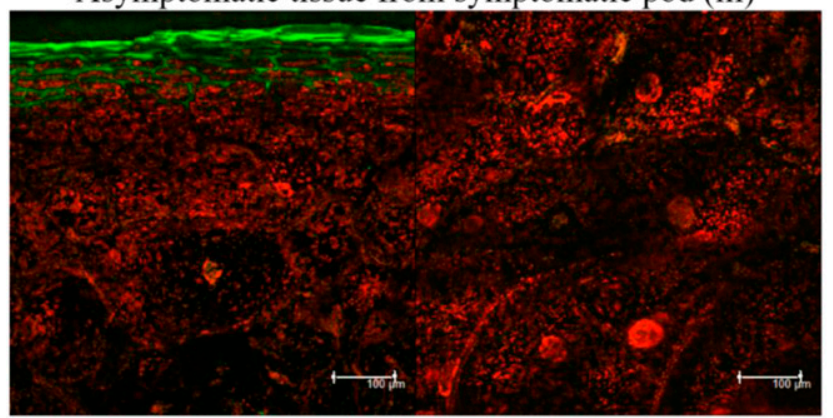

Symptomatic stip lesion tissue from symptomatic pod (iv)

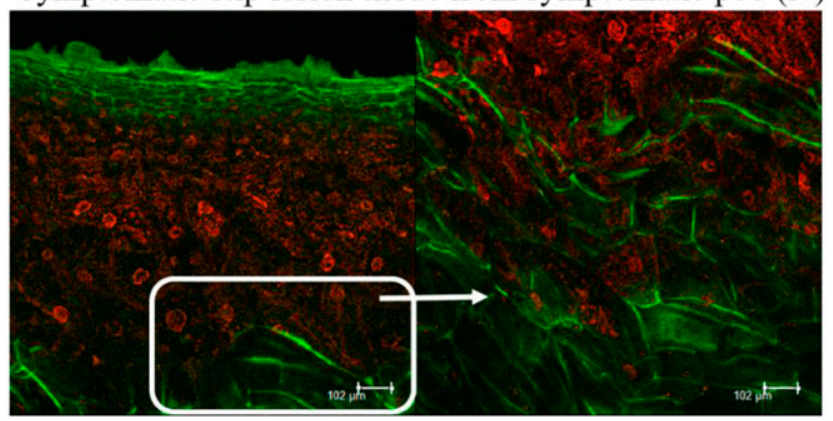

Fig. 5. Confocal fluorescent imagery of the four described tissue classes (i, ii, iii, and iv) from New Mexican pod-type pepper. Confocal imagery followed the same pattern seen in stereo fluorescence microscopy in which, of the four tissue types studied, two visually distinct groups were apparent: asymptomatic and symptomatic. Bars $=100$ and $102 \mu \mathrm{m}$. 


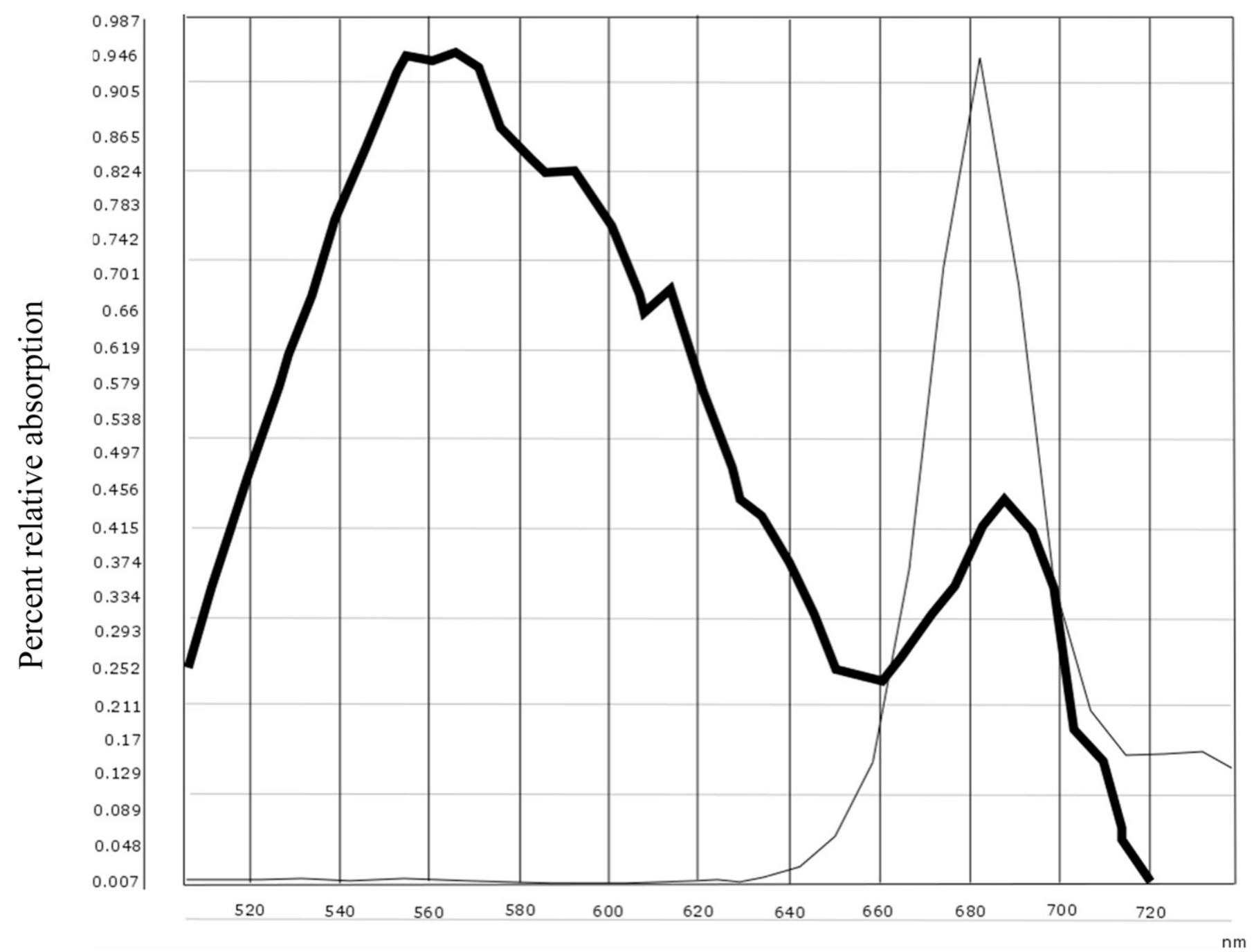

\section{Wavelength}

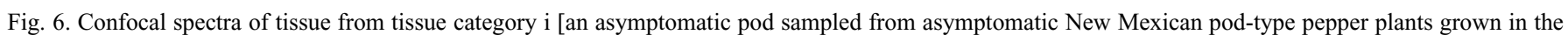
field (thin line)] compared with confocal spectra of tissue category iv [symptomatic lesion tissue sampled from symptomatic pods (thick line)]. The peaks are normalized to the predominant peak established at $100 \%$.

classes are shown in Table 2. Concentrations of malic acid, ethanolamine, phosphate, and serine 1 best fit general trend 1 and were significantly $(P<0.05)$ greater in symptomatic tissue compared with the other tissue classes.

Galactose was the only evaluated metabolite best characterized by general trend 2 . The concentration of this metabolite was detected at significantly lower concentrations in symptomatic tissue relative to the other three tissue categories. As shown in Table 2, galactose 1 was less present in symptomatic tissue relative to categories i $(P<0.05)$, ii $(P<0.01)$, or iii $(P<0.05)$.

General trend 3 best characterized the distribution of citric acid in the four tissue categories. The concentration of citric acid was significantly greater in symptomatic tissue relative to tissue categories i $(P<0.001)$ and ii $(P<0.0001)$. Because the concentration in category iii was only slightly elevated, it was not significantly different from any other tested tissue category.
Lower concentrations of oxalic acid, galactinol 1, and mannose 2 were detected in symptomatic tissue relative to both tissue categories $i$ and ii. The concentration of these metabolites in category iii was modestly lower relative to categories $\mathrm{i}$ and ii; however, the concentration was not significantly different from any of the evaluated tissue categories. The symptomatic tissue concentration of oxalic acid was statistically less compared with tissue categories i $(P<0.05)$ and ii $(P<0.05)$. Galactinol 1 concentration was significantly less in symptomatic tissue compared with tissue categories i $(P<0.001)$ and ii $(P<0.01)$. Last, mannose 2 was detected at a lower concentration in symptomatic tissue relative to tissue category i $(P<0.05)$.

\section{Discussion}

\section{Microscopy}

The stereo fluorescence and confocal micrographs in our study appear to show the loss of chlorophyll coinciding with the 


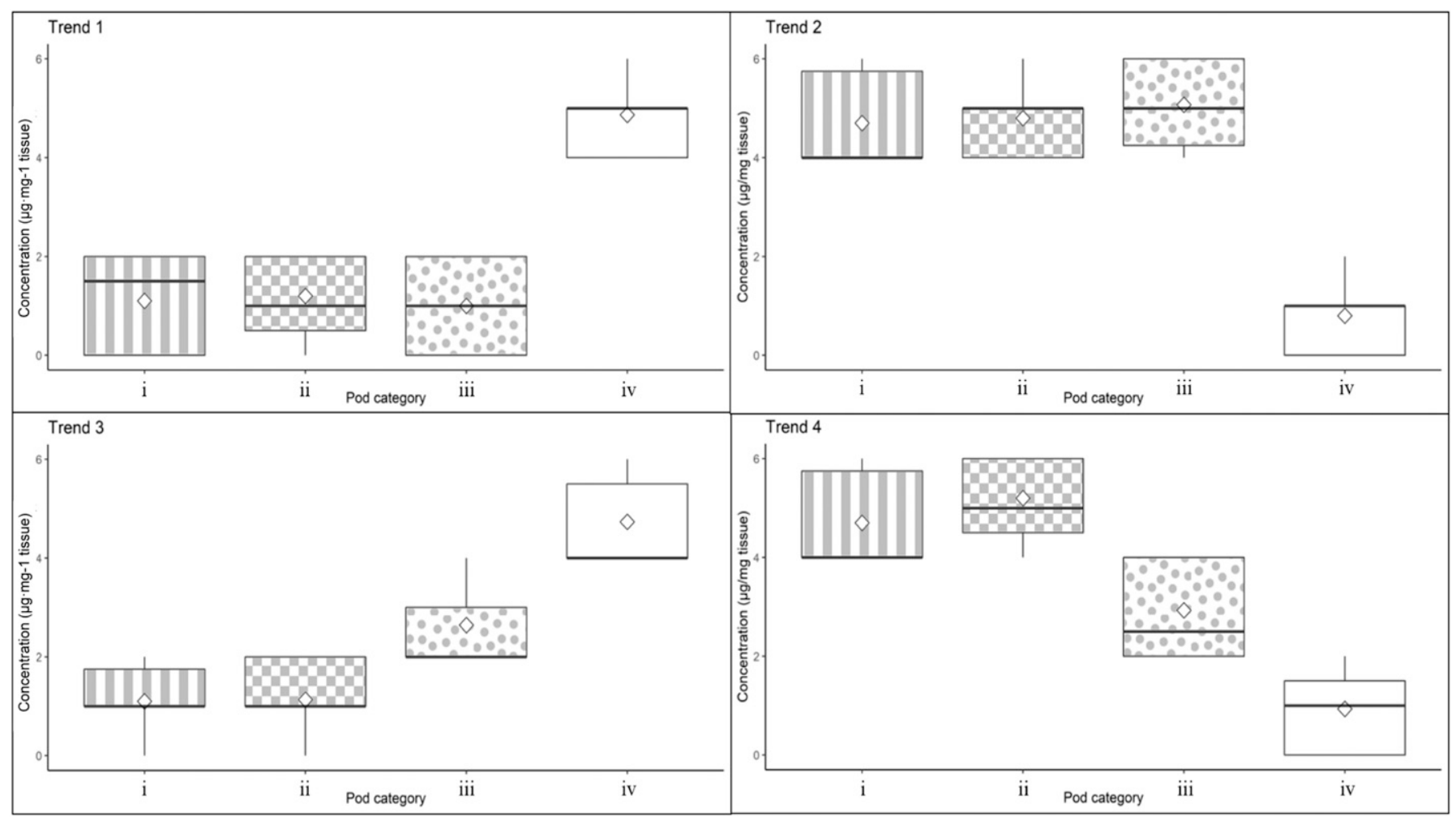

Fig. 7. Quantified metabolite concentrations in the four pepper tissue categories were found to follow one of four distinct metabolite profiles or trends. In trend 1 , a metabolite's concentration in the symptomatic tissue category (iv) was elevated in relation to tissue categories i, ii, and iii, and no tissue class was observed with an intermediate concentration. The inverse of this pattern was observed in trend 2 , in which a metabolite's concentration in the symptomatic tissue category (iv) was depressed in relation to $\mathrm{i}$, ii, and iii tissue categories, and no tissue class was observed with an intermediate concentration. Metabolites grouped into trends 3 and 4 were observed at an intermediate concentration for tissue class iii between that found in tissue categories i, ii, and iv. In trend 3 , a metabolite's concentration in the symptomatic tissue category was elevated relative to tissue categories i and ii; iii fell somewhere intermediate between the former (iv) and later (i and ii) tissue categories. Last, in trend 4, metabolites were observed at an intermediate concentration in iii tissue; the concentration was significantly less in tissue category iv relative to $i$ and ii.

emergence of a new fluorescent signal in symptomatic tissue (Figs. 3C and D, and 6). Fluorescence disappeared altogether at complete cell death in a fully developed stip lesion (Fig. 3D). This fluorescence corresponds with lesions visible to the naked eye and is not present in asymptomatic tissue (Fig. 4). Contrary to the findings of Aloni et al. (1994), chelated oxalic acid was not observed in symptomatic tissue (J.C. Fulton, P. Cooke, and M.E. Uchanski, unpublished energy-dispersive X-ray spectroscopy data).

Confocal emission spectra showed a peak centered at $\approx 680$ $\mathrm{nm}$, which corresponds with the emission spectra of chlorophyll $\alpha$ (Pedrós et al., 2008) (Fig. 6), whereas a broad peak extending from 500 to $700 \mathrm{~nm}$ was present in symptomatic tissue, which corresponds with the photosynthetically active radiation spectrum typically absorbed by healthy plants and associated pigments (Kume, 2017).

\section{Metabolomics}

High-PERformance liquid Chromatography. HPLC indicated that lutein concentration was the lowest in symptomatic stip lesion tissue from symptomatic pods, whereas capsanthin and zeaxanthin was highest with asymptomatic tissue from symptomatic pods (trend 3; Table 1). Lutein is an evolutionarily conserved xanthophyll widely shared by the plant kingdom. It binds with the light-harvesting antenna complexes of photosystem II, where it stabilizes antenna proteins, assists in photosynthesis by transferring energy absorbed by these antennae to chlorophyll, and provides photoprotection by quenching triplet excited chlorophyll molecules $\left({ }^{3} \mathrm{Chl}\right)$ (Jahns and Holzwarth, 2012). Without quenching, it is probable that the ${ }^{3} \mathrm{Chl}$ molecules would interact with diatomic oxygen to produce reactive oxygen species, which can be deleterious to the cellular machinery (Havaux, 1998). In our study, chlorophyll in symptomatic stip lesion tissue is notably absent, which is possibly the result of this type of damage.

Chlorophyll degrades during the normal ripening process (Borovsky and Paran, 2008). Furthermore, capsanthin and zeaxanthin accumulate in maturing cells whereas lutein decreases (Contreras-Padilla and Yahia, 1998; Hornero-Méndez et al., 2000). We observed that chlorophyll degraded and lutein accumulated (trends 2 and 3) (Table 1) in the pod areas defined by stip lesions. Stip symptoms appear to be localized portions of the pod that show characteristics of maturation and senescence whereas the rest of the pod appears normal. Meanwhile, asymptomatic tissue from symptomatic pods had intermediate quantities of capsanthin and zeaxanthin [trend 3 (Table 1), relative increase changes (Fig. 7)].

GAS CHROMATOGRAPHY-MASS SPECTROMETRY. Changes in primary and secondary metabolites similar to those described 
Table 1. The significance of post hoc (Tukey's honestly significant difference test) metabolite concentration differences among four evaluated pepper tissue categories.

\begin{tabular}{lcccccc}
\hline & \multicolumn{6}{c}{ Tissue category } \\
\cline { 2 - 7 } Metabolite & i-iv & i-iii & ii-iv & ii and iii & iii and iv & Trend \\
\hline Lutein & $* * * *$ & NS & $* * * *$ & NS & $* * * *$ & 2 \\
Capsanthin & NS & NS & NS & NS & NS & 3 \\
Zeaxanthin & $* * * *$ & $*$ & $* * * *$ & $* *$ & NS & 3 \\
Ethanolamine & $*$ & NS & $* * *$ & NS & $* * *$ & 1 \\
L-malic acid & $*$ & NS & $* * *$ & NS & $* * * *$ & 1 \\
Phosphate & $*$ & NS & $* *$ & NS & $*$ & 1 \\
Serine 1 & $* *$ & NS & $* * * *$ & NS & $* *$ & 1 \\
Galactose 1 & $*$ & NS & $* *$ & NS & $*$ & 2 \\
Citric acid & $* * *$ & NS & $* * * *$ & NS & NS & 3 \\
Galactinol 1 & $* * *$ & NS & $* *$ & NS & NS & 4 \\
Mannose 2 & $*$ & NS & NS & NS & NS & 4 \\
Oxalic acid & $*$ & NS & $*$ & NS & NS & 4
\end{tabular}

$\mathrm{i}=$ asymptomatic pod from asymptomatic plant; ii = asymptomatic pod from symptomatic plant; iii = asymptomatic tissue from symptomatic pod; iv = symptomatic stip lesion tissue from symptomatic pod. For explanation of Trends, see Fig. 7 caption.

NS, *, **, ***, $* * * *$ Nonsignificant or significant at $0.05,0.01$, 0.001 , or 0.0001 , respectively.

earlier were also detected by GC-MS. For example, we noted a decrease in oxalic acid (Tables 1 and 2). Jang et al. (2015) documented a decrease in the concentration of oxalic acid throughout maturity, and an increase in L-serine, citric acid, and L-asparagine. Gross et al. (1986) showed a decrease in D-galactose and mannose 2 during fruit ripening, which is necessary for cell wall degradation. Osorio et al. (2012) reported a significant decline in galactinol during ripening. Barrera et al. (2008) observed an increase in L-malic acid in two of the four hot-pepper cultivars studied, and Kang et al. (2002) found that ethanolamine has been shown to hasten fruit ripening and color change.

\section{Conclusions}

Our results suggest localized cell clusters that show stip symptoms enter premature fruit during maturation and early senescence of pod tissue. This is first suggested by the loss of chlorophyll in symptomatic tissue and the dampened absorption spectra in the photosynthetically active spectrum $(400-700 \mathrm{~nm})$. We documented imagery showing an apparent change of fluorescence (Fig. 3C and D) and the intermediate concentrations of capsanthin, zeaxanthin, citric acid, galactinol, mannose, and oxalic acid in asymptomatic tissue from symptomatic pods.

As described, the concentration of metabolites found to be significantly different in symptomatic stip lesion tissue changed similarly during the natural maturation and/or senescence processes. However, during instances of symptom expression, localized areas of an otherwise physiologically immature (i.e., green)
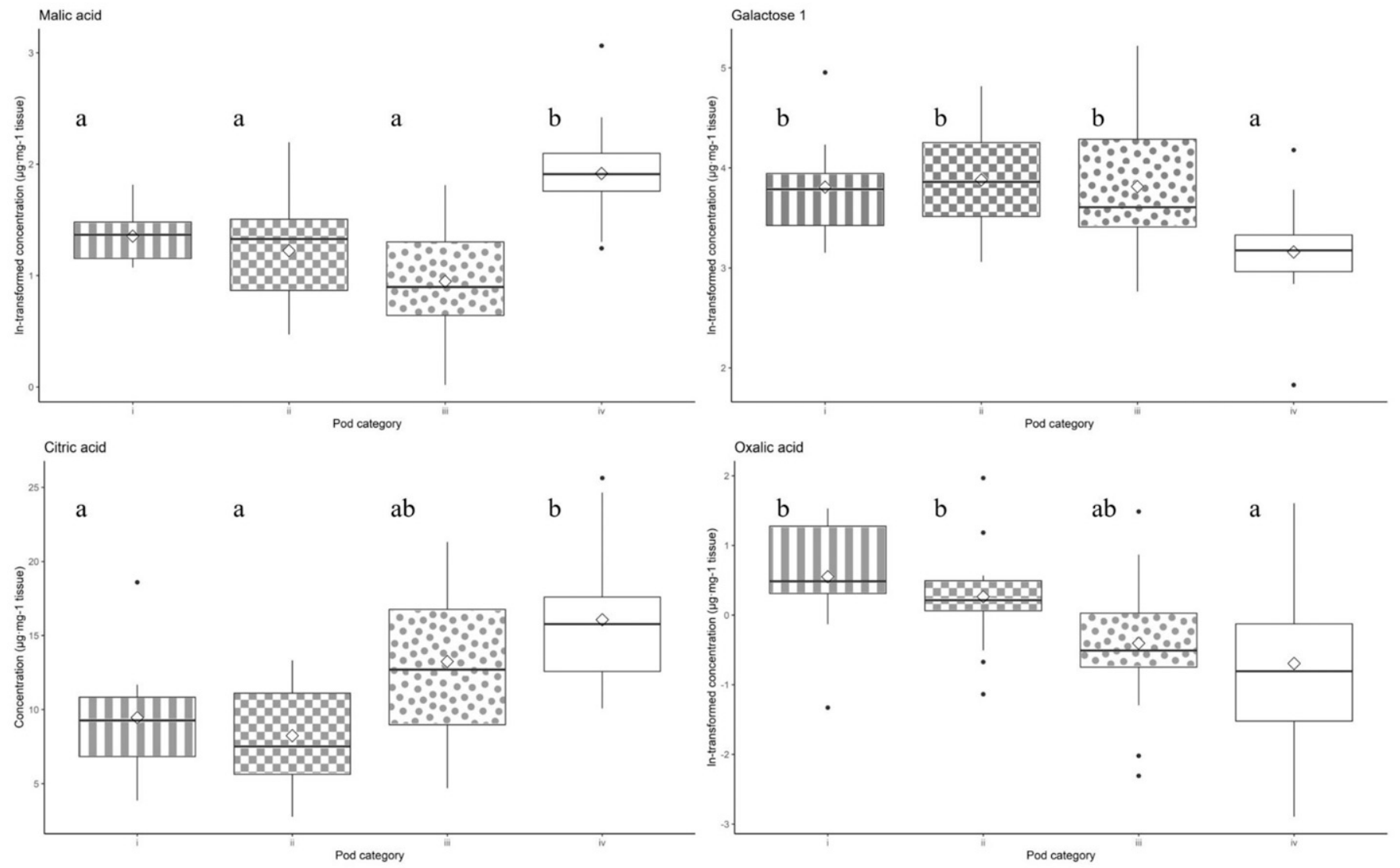

Fig. 8. Concentration differences among four classes of pepper pod tissue (i, ii, iii, and iv) of four metabolites (malic acid, galactose 1, citric acid, and oxalic acid) representing the four general concentration trends observed. Tukey's honestly significant difference test was used to test pairwise combinations. Significant differences are shown by lowercase letters. 
Table 2. Probability values for post hoc [Tukey's honestly significant difference (HSD) test] metabolite concentration comparisons trending among four evaluated pepper tissue categories.

\begin{tabular}{lcl}
\hline Metabolite & Comparison (Tukey's HSD) & $P$ value \\
\hline Malic acid & i-iv & $<0.05$ \\
& ii-iv & $<0.001$ \\
iii and iv & $<0.0001$ \\
Galactose & i-iv & $<0.05$ \\
& ii-iv & $<0.01$ \\
iii and iv & $<0.05$ \\
Citric acid & i-iv & $<0.001$ \\
& ii-iv & $<0.0001$ \\
Oxalic acid & i-iv & $<0.05$ \\
& ii-iv & $<0.05$ \\
\hline
\end{tabular}

$\mathrm{i}=$ asymptomatic pod from asymptomatic plant; $\mathrm{ii}=$ asymptomatic pod from symptomatic plant; iii = asymptomatic tissue from symptomatic pod; iv = symptomatic stip lesion tissue from symptomatic pod.

pod were observed to change. Our study was unable to confirm the hypothesis presented by Aloni et al. (1994) that chelated oxalic acid was the proximal cause of stip lesions; however, it is possible that intracellular damage could occur during nutrient accumulation and storage. Last, our study describes the unique fluorescence signature of this disorder and presents metabolite results that suggest localized cell maturation and necrosis (tissue category iv) (Figs. 3 and 4).

\section{Literature Cited}

Aloni, B., L. Rylski, and Z. Zaidman. 1994. The effect on nitrogen fertilization and shading on the incidence of 'colour spots' in sweet pepper (Capsicum annuum) fruit. J. Hort. Sci. Biotechnol. 69:767773, doi: 10.1080/14620316.1994.11516511.

Barrera, J.A., M.S. Hernandez, L.M. Melgarejo, O. Martinez, and J.P. Fernandez-Trujillo. 2008. Physiological behavior and quality traits during fruit growth and ripening of four Amazonic hot pepper accessions. J. Sci. Food Agr. 88:847-857, doi: 10.1002/jsfa.3161.

Boeckling, C.D., I.R. Reddy, A.L. Duran, X. Zhao, and L.W. Sumner. 2006. MET-IDEA: Data extraction tool for mass spectrometry-based metabolomics. Anal. Chem. 78:4334-4341, doi: 10.1021/ac0521596.

Borovsky, Y. and I. Paran. 2008. Chlorophyll breakdown during pepper fruit ripening in the chlorophyll retainer mutation is impaired at the homolog of the senescence-inducible stay-green gene. Theor. Appl. Genet. 117:235-240, doi: 10.1007/s00122-008-0768-5.

Contreras-Padilla, M. and M. Yahia. 1998. Changes in capsaicinoids during development, maturation, and senescence of chile peppers and relation with peroxidase activity. J. Agr. Food Chem. 46:20752079, doi: 10.1021/jf970972z.

Escandón, M., M. Meijón, L. Valledor, J. Pascual, G. Pinto, and M.J. Cañal. 2018. Metabolome integrated analysis of high-temperature response in Pinus radiata. Front. Plant Sci. 9:485, doi: 10.3389/ fpls.2018.00485.

Feigin, A. and B. Sagiv. 1987. Excessive nitrogen fertilization enhances "colour spots" in pepper fruits. Hassadeh 67:1564-1566. (in Hebrew).

Fulton, J.C., R. Steiner, J. Colee, and M.E. Uchanski. 2021. The development and progression of stip, a reputed physiological disorder, in two pepper (Capsicum annuum) cultivars grown in a greenhouse. Eur. J. Hort. Sci. 86:3.
Fulton, J.C. and M.E. Uchanski. 2017. A review of chile pepper (Capsicum annuum) stip: A physiological disorder of peppers. HortScience 52:4-9, doi: 10.21273/HORTSCI11123-16.

Gross, K.C., A.E. Watada, M.S. Kang, S.D. Kim, K.S. Kim, and S.W. Lee. 1986. Biochemical changes associated with the ripening of hot pepper fruit. Physiol. Plant. 66:31-36, doi: 10.1111/j.1399-3054.1986. tb01227.x.

Havaux, M. 1998. Carotenoids as membrane stabilizers in chloroplasts. Trends Plant Sci. 3:147-151, doi: 10.1016/S1360-1385(98)01200-X.

Hibberd, A.M. 1981. Symptoms of and variety reaction to green pitting, a non-pathological disorder of red bell peppers in Queensland. Queensland J. Agr. Animal Sci. 38:47-53.

Hornero-Méndez, D., R. Gómez-Ladrón de Guevara, and M. Minguez-Mosquera. 2000. Carotenoid biosynthesis changes in five red pepper (Capsicum annuum L.) cultivars during ripening: Cultivar selection for breeding. J. Agr. Food Chem. 48:3857-3864, doi: 10.1021/jf991020r.

Jahns, P. and A.R. Holzwarth. 2012. The role of the xanthophyll cycle and of lutein in photoprotection of photosystem II. Biochim. Biophys. Acta Bioenerg. 1817:182-193, doi: 10.1016/j.bbabio.2011.04.012.

Jang, Y.K., E.S. Jung, H. Lee, D. Choi, and C.H. Lee. 2015. Metabolomic characterization of hot pepper (Capsicum annuum 'CM334') during fruit development. J. Agr. Food Chem. 63:9452-9460, doi: 10.1021/acs.jafc.5b03873.

Kang, C.K., Y.L. Yang, G.H. Chung, and J.P. Palta. 2002. Ripening promotion and ethylene evolution in red pepper (Capsicum annuum) as influenced by newly developed formulations of a natural lipid, lysophosphatidylethanolamine. Acta Hort. 628:317-322, doi: 10.17660/ActaHortic.2003.628.38.

Kind, T., G. Wohlgemuth, D.Y. Lee, Y. Lu, M. Palazoglu, S. Shahbaz, and O. Fiehn. 2009. FiehnLib: Mass spectral and retention index libraries for metabolomics based on quadrupole and time-of-flight gas chromatography/mass spectrometry. Anal. Chem. 81:10038-10048, doi: $10.1021 /$ ac9019522.

Kume, A. 2017. Importance of the green color, absorption gradient, and spectral absorption of chloroplasts for the radiative energy balance of leaves. J. Plant Res. 130:501-514, doi: 10.1007/ s10265-017-0910-z.

Michailidis, M., E. Karagiannis, G. Tanou, K. Karamanoli, A. Lazaridou, T. Matsi, and A. Molassiotis. 2017. Metabolomic and physico-chemical approach unravel dynamic regulation of calcium in sweet cherry fruit physiology. Plant Physiol. Biochem. 116:68-79, doi: 10.1016/j. plaphy.2017.05.005.

Moradi, P., B. Ford-Lloyd, and J. Pritchard. 2017. Metabolomic approach reveals the biochemical mechanisms underlying drought stress tolerance in thyme. Anal. Biochem. 527:49-62, doi: 10.1016/j. ab.2017.02.006.

Osorio, S., R. Alba, Z. Nikoloski, A. Kochevenko, A.R. Fernie, and J.J. Giovannoni. 2012. Integrative comparative analyses of transcript and metabolite profiles from pepper and tomato ripening and development stages uncovers species-specific patterns of network regulatory behavior. Plant Physiol. 159:1713-1729, doi: 10.1104/pp.112.199711.

Pedrós, R., I. Moya, Y. Goulas, and S. Jacquemoud. 2008. Chlorophyll fluorescence emission spectrum inside a leaf. Photochem. Photobiol. Sci. 7:498-502, doi: 10.1039/B719506K.

Richins, R. D., J. Kilcrease, L. Rodriguez-Uribe, and M.A. O'Connell. 2014. Carotenoid extraction and quantification from Capsicum annuum. Bio Protoc. 4:e1256.

Smith, R., B. Mullen, and T. Hertz. 1995. Epidemiology and control of pepper stip. California Pepper Comm., Dinuba, CA (abstr.).

Villalon, B. 1975. Black spot: A non-parasitic disease of bell pepper fruit in the lower Rio Grande Valley of Texas. Plant Dis. Rep. 59: 926-927. 